3) Ueber Prifung antimonhaltiger Substanzen auf Arsenik durch das Löthrohr. - Es ist bekannt, wie das Löthrohr hier in den meisten Fällen als sehr entscheidend auftritt - Nichts Neues will ich in dieser Beziehung (leider stets als Schuiler) mittheilen, sondern nur auf einen Umstand aufmerksam machen,' welcher leicht zu falschen Schliissen Veranlassung bicten könnte.

Um z. B. bei dem Antimonmetalle die Gegenwart des As (in differenten Verb.) nachzuweisen, wird nicht sel. ten das Experiment angewandt, schmelzendes $\mathrm{Sb}^{\circ}$ in eine Papierkapsel zu schütten, um bei den Rotationen den AsGeruch wahızunehmen. - Hier tritt nun aber leicht der Fall ein, dass Papier mit Smalte gefärbt ist, und nun der Arsenikgeruch durch $\mathrm{C}$ des Papiers, wie auch durch die As + Co-Verbindung zum Vorschein kömmt.

\title{
Chemische Untersuchung des Cortex Sambuci interior:
}

\section{von \\ II. Kr a emer in Firchen.}

Dic mittlere grüne Rinde des Hollunders - Cortex Sambuci interior s. mediana - scheint in früheren Zeiten in nicht geringem Ansehen gestanden zu haben. Remedium est insigne antihydropicum, serum educit, ictericis convenit et menstrua movet, sagt die Würtemberger Pharmakopöe von 1760 pag. 104, und während diese Eigenschaften bei den neueren Aerzten ausser Beachtung gekommen sind, weiss sie hier und da der Landmann recht wohl zu benutzen, in dessen Händen die genannte Rinde ein sicheres drasticum, immer aber auch ein gefährliches Mittel bleibt. Schon die Alten haben ihre medicinischen Kräfte gekannt und angewandt. Hippokrates rechnet den Hollunder $(\dot{\alpha} * t \eta)$ zu denjenigen Mitteln, welche mehr abführend als

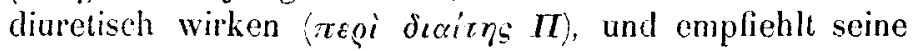
Anwendung an mehreren Stellen Dioskorides /de mat. med. L. IV.C. 175) rühmt die Wirkung von Sam- 


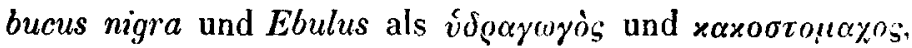
während Galen L. VI. C. 21 nur ihre äussere Anwendung gekannt zu haben scheint. Plinius (H. n. LXXIV. C. 35) bemerkt, dass die innere Rinde von Sambucus nigra mit weissem Wein genommen, Abfihren errege. In Frankreich ist, nach dem Zeugnisse Soubeiran's (Traité de Pharm. 1837. p. 239) in nenerer Zeit die Wurzelrinde des Hollunders gegen Ascites wieder zu Ehren gekommen. Wiewohl die Materia medica an emetico-catharticis keinen Mangel leidet, so erlaube ich mir doch die Aufmerksamkeit der Aerzte auf ein so energisch wirkendes Mittel wieder hinzulenken, schon aus dem Grunde, weil es iberall leicht in tadelloser Beschaffenheit zu erhalten ist, was nicht von allen ähnlichen, namentlich nicht von der in ihrer Wirkung so nahe stehenden Gratiola officinalis gilt. Sechs Gran des durch Naceration mit Alkohol bereiteten Extractes, wovon die Rinde ungefähr 5 Procent liefert, bewirkten bei einem 32jährigen gesunden Manne mehrmaliges hefliges Erbrechen und darauf reichliche, ganz flussige Slibhle; und wohl ist anzunehmen, dass hei einer zu grossen Gabe Symptome der Darmentzündung eben so wohl entstehen können, wie nach dem Genusse der Blätter von Sambucus Ebulus.

Die mittlere grüne Rinde der zweijährigen Aeste von Sambucus nigra hat einen eigenthümlichen Geruch, ibereinstimmend mit dem der jungen Blätler dieser Pflanze, und einen faden, schwach billeren Geschmack. Das Decoct derselben, von schwach brauner Farbe, wurde durch Ammoniak stärker gebräunt, durch Eisenchlorürchlorid schwarz, durch neutrales essigsaures Bleioxyd, ebenso durch Quecksilberchlorid und salpetersaures Silberoxyd schmutzig-weiss gefallt. Brechweinstein bewirkte darin erst nach einiger Zeit Trübung, Oxalsäure und Chlorbaryum geringen Niederschlag.

Das uber die frische Rinde abgezogene Wasser hatte einen eigenthümlichen, dem der Aqua cort. Viburni nicht unähnlichen Geruch, und röthete schwach das Lackmuspapier. Durch Digestion mit kohlensaurem Baryt, Filtriren 
und Abdampfen bei gclinder Wärme wurde daraus ein Salz erhalten, wolches im Geruch und allen übrigen Reactionen mit dem in diesem Archiv Bd. XL. p. 269 erwähnten viburnumsauren Baryt ibereinstimmte. Das beim Abdampfen dieser Salylisung übergehende Wasser besass noch einen eigenthimlichen Geruch, und enthielt also wohl noch Spuren eines atherischen Oels, welches jedoch nicht abgeschieden werden konnte.

Mit Wasser zerstossen und ausgepresst lieferte dio frische Rinde einen bräunlichen, mach dem Filtriren klaren Saft, wetcher beim Kochen Flocken von coagulitem Pllan. zeneiwciss ansschied.

Die in Wasserbade getrocknete Rinde wurde successive mit Acther, Alkohol, kaltem und kochendem Wasser, verdiunter Salzäure und verdiinnter Kalilauge ausgezogen.

Der Actherauszug besass eine schön grine Farbe. Nach dem Abdestilliren des Acthers und Verdunsten des Ruickstantes im Wasserbarlo blich cin grües schmieriges Extract zuriuck, aus welchem Wasser eine geringe Menge des Eisenoxyduloxydsalze schwarz fallenden Gerbestoffs auszog. Kalter Alkohol lostc hierauf die Masse unter Zuricklassung einer grinen weichen Substanz mit gruner Farbe aut

Dicse Alkohollösung des Aeherextractes wurde mit einei alkoholischen Lösung von essigsaurem Bleioxyd verselzt, und in dio von dem daduch entstandenen hellgrinen Niedershage abfiltrire noch griin gefarbte Flis* sigkeit so lange sclwetclwasserstof goleitet, als Schwefelblei nioderliel. Xach dem Abfitrier desselben zoigte sie eino hellbrane Farbo, and hinterliess nach dem Verdunsten ein hellbraunes durchsichtiges Harz, welches den letzlen Gehalt an Wasser und Essigsaure erst durch Schmelzen verlor und hierauf eine leicht zerreibliche Masse darstelle In Acther, Schwefelkohlenstoff, Terpentin - und Mandelol löste sich dieses Marz leicht, weniger leicht in Alkohol, aus dessen kochend gesätligter Auflösung es beim Erkalten zum Theil sich pulverförmig wicder ausschied. Dio Alkohollösung hatio einen bitteren, 
hintennach kratzenden Geschmack und röthete Lackmus nicht. Es löste sich nicht in Essigsäure, auch nicht in kaustischer Kalilösung und Ammoniakliquor, und die durch Wasser bewirkte Trübung der Alkohollösung verschwand nicht durch Zusat\% von Kalilauge. Es gehört also zu den ganz indifferenten Harzen.

Der Bleioxydniederschlag wurde mit Alkohol angerüht und ebenfalls durch Schwefelwasserstoff zersetzt. Die von dem Schwefelblei abfiltrirte Fliissigkeit hinterliess nach dem Verdamplen eine dunkelbraune schmierige Masse von eigenthiimlichem unangenehmem Geruch, welche bei gelinder Wäme flissig wie Oel wurde, auf Papier Fettlecke machte und beim Zersetzen durch Hitze den eigenthimlichen Geruch fetter Körper verbreitete. Dieses Felt löste sich leicht in Acher und Schwefelkohlenstoff, fetten und flichigen Oelen, und zicmlich leicht in Alkohol, welche Lösung das Lackmuspapier röblhete. Mit Kalilauge verseifte es sehr leicht. Wurde diese Seife mit Schwefelsaure zerlegt, so entwickelte sich der unangenehme Geruch des Fettes noch deutlicher. Mit chemisch reinem Salpeter verbrannt, hinterliess es eine Salzmasse, welche nach dem Uebersälligen durch reine Salzsäurc durch Chlorbarium gefält wurle. Es enthält also Schwefel. Man könnte diesen Schwefelgehalt ableiten von der Behandlung des Bleiniederschlages mit Schwefelwasserstoff, indess zeigte das mit Wasser ausgezogene Aetherextract dieselbe Reaction. Ob und wiefern dieses Fett in Bezie. hung stehe zur Viburnumsäure, wie sich wohl nach Analogie der fliichtigen Fettäuren des Thierreichs vermuthen lässt, müssen spätero Versuche entscheiden.

Der in Alkohol nicht golöste griine Rückstand des Aetherextracts wurde leicht von kochendem Alkohol aufgenommen, bei dessen Erkalten sich eine etwas grün gefärbte wachsarlige Materic abschied. Die hiervon abfiltrirte Flüssigkeit setzté beim langsamen Verdampfen Chlorophyll als grünen erlartigen Ueberzug an die Wände des Gefasses ab, wolches in starker Salzsaure sich mit grüner Farbe auflöste. 
Der Alkoholauszug der Rinde war hellbraun, reagirte sauer und hinterliess ein braunes, durchsichtiges, leicht zu pulverndes, hygroskopisches Extract, welches zurn grössten Theil vonWasser aufgenommen wurde. Die wässerige Lösung fällte Eisenoxyduloxydsalze schwarz. Der Gerbsäuregehalt dersclben wurde durch Bleizackerlösung gefällt, das überschussig zugesetzte Bleisalz durch Schwelelwasserstoff entfernt, die Flüsigkeit filtrirt und abgedampft. Das zurückbleibende Extract schmeckte suisslich und zugleich salzartig, und gab durch die Kali-Kupferprobe Traubenzucker zu erkennen. In der Asche fand sich kohlensaures kali. Um die mit dem Kali verbundene Säure zu bestimmen, wurde der Bleiniederschlag mit Wasser ausgekocht und siedendheiss filtrirt, worauf sich beim Erkalten apfelsaures Bleioxyd in langen Nadeln ausschied. - Der in Wasser unlösliche Theil des Alkoholauszugs verhielt sich wie das oben erwahnte Gemisch von Harz und Fett des Aetherauszugs.

Das mit kaltem Wasser bereitete Infusum der Rinde war hellbraun, geschmacklos, tribte sich nicht beim Erhitzen und lieferte nach dem Verdunsten eine durchscheinende hellbraune Masse, die nach dem Behandeln mit kochendem Alkohol fast farblos zurückblieb. Sie löste sich in wenigem Wasser zu einer schleimigen Flüssigkeit auf, welche durch Alkohol flockig, durch Bleizucker - und Alaunlösung gallertartig, und durch Kieselfeuchtigkeit nicht gefallt wurde. Sic gehört also zu derjenigen Art Gummi, welche Liebig als Schleim auffuhrt. Nach dem Verbrennen blieb eine geringe Menge einer aus kohlensaurem Kalk bestehenden Asche zurück; sie enthielt also noch cin pflanzensaures Salz dieser Base, wahrscheinlich äpfelsauren Kalk. - Der nach dem Verdunsten des Alkobols zurückbleibende Extraclivstoff scbmeckte gelinde bitter, löste sich leicht in Wasser, und gab mit essigsaurem Bleioxyd, salpetersaurem Quecksilber - und Silberoxyd Niederschliage. Das Decoct der Rinde, von schleimiger Beschal. fenheit und geschmacklos, enthielt Amylum, welches durch Jodwasser sehr deutlich angezeigt wurde. Zur Trockne 
verdunstet, trat der Ruickstand an Alkohol den oben erwähnten Extractivstoff, an kaltes Wasser Gummi ab, und zuruick blieb eine hellbraune Masse, welche in wenigem kochendem Wasser zu einem Kleister aufquoll. Sowohl das Decoct als der mit kaltem Wasser bereitete Auszug enthielten die schwefelsauren und salzsauren Salze von Kalk und Kali.

Der mit verdiunnter Salzsäure erhaltene Auszug war rothbraun. Er wurde im Wasserbade bis zur duinnen Honigconsistenz abgedampft und mit Alkohol versetzt, welcher braune, schleimige Flocken fallte. Diese mit Alkohol wohl ausgewaschen, waren geschmacklos, lösten sich in Wasser zu einer schleimigen durch Alkohol fällbaren Flüssigkeit auf, und verhielten sich überhaupt wie künstliches Gummi, welches durch Salzsäure aus amylumbaltigen Pflanzentheilen ausgezogen und bei dieser Operation erst gebildet wird. In der rothbraunen spirituösen Flüssigkeit zeigten Eisensalze Gerbsäure an. Zur Trockne verdunstet und mit Wasser behandelt, blieb eine geringe Menge Extractabsatz zuriick. Die Asche des salzsauren Auszugs bestand aus Chlorcalcium, schwefelsaurem und phosphorsaurem Kalk, Talkerde und Chlorkalium.

Das alkalische Decoct der Rinde von rothbrauner Farbe wurde im Wasserbade bis auf die Hälfte verdunstet und mil Essigsäure versetzt, wodurch ein flockiger, brauner Niederschlag entstand, welcher auf einem Filtrum gesammelt und wohl ausgewaschen an kochende Essigsäure coagulirtes Pflanzeneiweiss abtrat, während ein brauner Körper zurückblieb, der sich durch sein Verha!ten gegen Kali als Pectin charakterisirte.

Die Asche der nicht ausgezogenen Rinde bestand aus kohlensaurem und schwefelsaurem Kali nebst Chlorkaliun, kohlensaurem und phosphorsaurem Kalk und Talkerde, Kieselsäure und Spuren von Eisenoxyd.

Nach den angefubrten Versuchen enthält die miltlere Rinde von Sambucus nigra Viburnumsäure, Spuren ätherischen Oels, Pflanzeneiweiss, indifferentes Harz, saures schwefelhaltiges Fett. Wachs, 


\section{Kraemer; Untersuchung des Cortex Sambuci interior.}

Chlorophyll, eisenbläuende Gerbsäure, Trau= benzucker, Gummi, Extractivst off, Amylum, Pectin, äpfolsaures Kali, äpfelsauren Kalk, schwefelsauresKali, schwefelsaurenKalk, Ch] orkalium, phosphorsauren Kalk, Talkerde, Kieselsäure und Eisenoxyd.

Das Vorkommen der Viburnumsäure in einer officinellen Pllanzengattung giebt derselben ein neues Interesse für die Pharmaccuten. Ich bemerke hier vorläufig, dass ich cliese Säure, ausser in der Rinde, auch in den Beeren und in den Blumen von Sambucus nigra aufgefunden habe. Sie kornmt in der Aqua florum Sambuci mit Ammoniak verbunden vor, neben atherischem Oel und kohlensaurem Ammoniak, welches letztere schon Gleitsmann darin intdeckt hat. Man darf nur cinige Unzen dieses Wassers, mit einigen Tropfen kaustischer Kalifluissigkeit versetzl, im Wasserbade zur Trockne verdampfen, den Salzriickstand in einer ganz geringen Menge Wasser aufnehmen, hie Flüssigkcit in cin Drachmenglas geben, mit Phosphorsäure versetzen und mässig erwärmen, um den eigenthümlichen Geruch der Viburnumsäure zu bemerken. Die Dämpfe dieses Gemisches röthen Lackmuspapier bleibend. Der gelbliche Niederschlag, welcher in sehr concentrirter Aq. Sambuci durch Bleiessig entsteht, enthält basisch-viburnumsau. res und kohlensaures Bleioxyd nebst ätherischem Oel.

\section{Zusatz der Redaction.}

E. Simon fand das wirksame Princip der Fliederwurzelrinde im Weichharze derselben. Einen krystallisirten Stoff find er nicht. Die bei $20^{\circ} \mathbf{R}$ getrocknete Rinde wurde gepulvert mit Alkohol von 0,823 so oft extrahirt, als sich noch elwas löste; von den geklärten Tincturen wurde der Weingeist im Wasserbade abdestillirt, die syrupartige Masse mit Acther gemischt und dann dem Ganzen durch Abdampfen die Consistenz eines dicken Extracts gegeben. 20 Gran desselben bewirkten 4-5maliges Erbrechen und eben so viele Stuhlgänge. (Annal.d. Pharm. Septbr. 1839.) 